\title{
A bestiary of digital monsters
}

\author{
Rachel Douglas-Jones ${ }^{10000-0001-9562-6572]}$, John Mark Burnett, [0000-0002-1310-5050] Marisa \\ Cohn, Christopher Gad, Michael Hockenhull[ ${ }^{[0000-0002-2670-2102]}$ Bastian Jørgensen, James \\ Maguire, Mace Ojala [0000-0002-9546-1736], Brit Ross Winthereik ${ }^{[0000-0002-1837-2385]}$ \\ ${ }^{1}$ IT University of Copenhagen, Rued Langaards Vej 7, 2300, Copenhagen, Denmark \\ rdoj@itu.dk; jmbulitu.dk; mcoh@itu.dk; chgalitu.dk: \\ michh@itu.dk; bmjo@itu.dk; jmag@itu.dk; maco@itu.dk; brwi@itu.dk
}

\begin{abstract}
This article puts forward a bestiary of digital monsters. By bringing into dialogue scholarship in monster theory with that in science and technology studies, we develop the idea of the bestiary as a way of exploring sites where digital monsters are made. We discuss the role of bestiaries in narrating anxieties about the present. We proceed to populate our bestiary with various sociotechnical 'beasts' arising in collaborative research project on new data relations in Denmark. The paper argues for the place of the ever-incomplete bestiary in understanding digital monsters, for the bestiary's role as gathering point within our project, and for its capacities to speak beyond a single research setting. Through the bestiary, we look toward the ways we already live with monsters and to the forms of analysis available for describing the beasts in our midst.
\end{abstract}

Keywords: bestiary, digital, monster.

\section{$1 \quad$ Introduction}

Today's digital monsters can be loud, crashing through headlines and twitter storms shrouded in the armor of controversy, revelation and shock value. They can also become virtually undetectable, creeping into our lives unnoticed. Moments of exposure highlight their monstrous contours: a technology previously benign flips and is suddenly problematic. Seen as though for the first time, monstrous beings are 'not yet recognized' [7: 386], existing at the edge of the known, on the cusp of the future. In moments of revelation, devices, platforms or softwares we have welcomed into our lives are suddenly distant. As digital technologies continuously transform who we are, including what we perceive as our needs, the sense is that they are always lurking around with their potential and unpredictable effects. We never know exactly when and where they may unnerve or even terrify us. In this way, they defy the border between real and imaginary.

In this article, we put forward a bestiary of digital monsters as a way of relating to the digital monstrous. Borrowing from early ways of identifying and telling stories 
about the things in our worlds with which we must live and learn to relate, the bestiary offers us a 'thought device' [10] through which the technological monstrous can be understood. In a series of collected interviews discussing the character of the future, the French philosopher Jacques Derrida argues that to be open to the future is to 'welcome the monstrous arrivant, to welcome it, that is, to accord hospitality to that which is absolutely foreign or strange' [7: 387]. As scholars studying acts that claim to bring the future into being, our task then, is necessarily one of living with monsters. We know that technological futures are themselves imaginative figurings [8, 4], making us careful about the devices we as analysts use in narration. Within this contemporary bestiary, therefore, the monstrous is not a property of an entity nor something inherently good 'gone wrong'. Instead, it emerges in a narrated relation, in which critical analysts of technology are themselves caught up [27].

The examples we put forward in the article, the 'beasts', arise in attempts to govern organizations, businesses and citizens. We are drawing on an ongoing, collective research project Data as Relation - Governance in the Age of Big Data. None of the beasts are technologies alone, isolated from the people who made, use, or discuss them. Instead, one of our objectives in thinking with the monster concept through a bestiary is to ensure that the concept of the monster does not 'other' the digital as untamed or alien. Our 'beasts' illustrate how that which is monstrous might emerge not as an object but as a practice, a habit, a sociotechnical assemblage. The analysis is informed by two key analytical repertoires, first, the critical theorist Jeffrey Jerome Cohen's Seven Theses of Monster Culture [5] and second, anthropologist and science and technology scholar Donna Haraway's work on the 'promise' of monsters [14]. In addition to work in Science and Technology Studies and Monster Theory, these two scholars in particular help us consider the 'ontological liminality' that is part of making monsters: the ongoing question, what are they? Cohen's seven foundational "breakable postulates" [5: 4] for example, range from concern with the body of the monster (thesis 1) to its role in bringing about category crises, or policing the 'borders of the possible' [5: 13]. His framework originates in cultural theory, marrying familiar western monsters with those of myth in his analyses of the vampire, the gargoyle, Godzilla, the Cyclops, King Kong and Alien. In turn, Donna Haraway, who is well known for thinking with a repertoire of figures such as the cyborg, oncomouse, or coyote, warns us against attempting to identify 'real' differences, the things that would make monsters 'other'. What she suggests instead is that we work to map some of the effects of difference. As she argues, the identification of 'real' differences 'invites the illusion of essential, fixed positions, while the second trains us to more subtle vision' [14: 300]. In bringing both Cohen's "breakable postulates" and Haraway's attention to the subtleties of difference-making into conversation with contemporary technologies, we develop the idea of the technological bestiary as a way of exploring the sites where the monstrous is made. The bestiary, we argue, can act as a gathering point, an object around which further communal exploration of life in the digital can take place. In what follows, we discuss the bestiary as a genre and form before going on to begin to populate our bestiary with empirically derived beasts, 'living beings' [7:386]. From ongoing research, our aim is to make the bestiary speak beyond the examples put forward here, to be part of a conversation about 
the emergence of monstrosity and a reflexivity about what such descriptions mean and do.

\section{A Bestiary}

A bestiary is a collection of monsters, real and imagined. Medieval bestiaries were collections of drawings and fables about many fascinating creatures with various capacities, conducts and patterns of life (including a variety of rocks) and were often intended as tools of education and instruction. The kinds of creatures described in such collections ranged from locally known species, to those known but never seen, to those mentioned in travelogues, and to those in the bible. Alongside these images and accounts were stories, moral tales that gave bestiaries a social role comparable with that of the fairytale. In contrast to later zoology handbooks, in a bestiary both 'known' and 'imaginary' monsters could cross species boundaries, taking on features and elements of other entities. Some bestiaries contained observations about species, subsequently refuted by natural philosophers, only to be later deemed real by modern science. Thus, these early books of beasts fulfilled a range of social and intellectual functions, acting not as imprecise zoology textbooks or religious texts, "but also a description of the world as it was known" [3]. They were multimedia devices that aimed to make the world known.

Creating a bestiary is also a work of describing the world. It is good to think with. While sources for thinking the monstrous change over time, our bestiary borrows from the characteristics of the medieval book, describing the emergent monster and telling stories about its everyday life and way of being. However, it also makes a number of liberal interpretive departures from the medieval style, working inventively with the genre to bring monsters (with and without bodies) to the fore, reflexively inserting the role of the analyst in their making and description. Crucially, digital monsters are both identified by field informants, objects of anxiety or unease, as well as by the authors as analysts and participants in ongoing studies. We have included beasts according to four guiding ideas.

First, rather than pointing to the physical form of objects in the world, the monsters that gain a place in the bestiary are visible through the effects of the differences that they make. Haraway describes the appearance of the effects of difference as a 'diffraction pattern' [14:300], a technique of attending to difference through its effects rather than through essentializing. As noted above, our collective curiosity hinges on newly emerging relations made through data, this attention to the effects of difference allows us to bring forward the power of the imaginary in shaping and re-shaping futures as digitization projects are born, gather pace, or evaporate.

Second, in line with this descriptive spirit, the work of a present-day bestiary is the work of figuring out what is monstrous, rather than simply identifying monsters [5]. The distinction is important: Including something in the bestiary is a move of calling forth, rather than calling out. Description is participation in the work of analysis. To name a beast is a domesticating move, which allows us disempower the potential threat posed by the undiagnosed and the unknown. It is also to make a value judgement, to 
diagnose its characteristics, and some normative work in deciding what is monstrous in our midst. Entries contain a critique of the making-monstrous, since the starting point is that the monstrous is neither a property of the research site, nor of the thing itself. The bestiary becomes a site to study potential, aftermath and description itself, bringing monsters into being in a way that does not parallel the revelatory mode of the news cycle, but is a more careful critique of those of us who, living in close analytical proximity with them, could make them accountable.

Third, we attend to monsters whose monstrosity is not merely given through appearance. In his analysis of Invisible Monsters, the literature scholar Jeffrey Weinstock describes a 'decoupling of monstrosity from appearance', with the monstrous 'reconfigured as a kind of invisible disease that eats away at the body and the body politic' [28:275]. He is thinking here of monsters that live amongst us undetected, forces that find their way into the 'crevices of everyday life' and the silent infiltrations that give rise to unease [28: 276]. Weinstock's analysis of figures such as the psychopath, the terrorist, the faceless corporation or government agency draws out a contemporary monstrosity manifest in invisibility and potential ubiquity [28: 276]. For our purposes, might Weinstock's attention to 'silent infiltration' help us handle the sense of creepiness that lingers around questions of privacy, data transfer or algorithmic processing? Before they become the 'loud' monsters that take up headline space in the latest data scandal, indeed, if they ever do, the undetected ubiquity of contemporary digital worlds should give us pause.

Finally, as with prior attempts to catalogue the monstrous, 'total inclusivity would not be possible' [23: 9, 26]. The bestiary, following this line of thinking, is put forward as an expandable exercise, yet one that is inherently incomplete. What a bestiary does is provide us with a space in which we can explore the capacities of description in our ethnographic narration, and remain open to bringing forward further monsters that emerge from observations made by those in the field and from our own senses of unease. The beasts of the bestiary thus exist in lateral relation to each other $[22,12]$, an analytical choice which refuses to privilege the position of the analyst or observer.

In this sense, the bestiary performs the messy work of the list, the gathering up of figures for the telling of stories that can 'stay with the trouble' [15]. The calling forth of monsters is not meant to fix their identity, but to work with the power of naming, to how we can work with these emerging forms of monstrosity, and consider the care, caution or antagonism with which they ought to be handled. The bestiary wards against a totalizing idea of the "digital monstrosity". As in a medieval bestiary, these beasts are not fixed, because our accounts are necessarily incomplete. As a lateral rather than taxonomic exercise, some beasts are hybridized from disparate accounts, others may turn out to be an exotification of the unknown mixed in with the real. We hope they may find recognition in the research of others. Regardless, the work that they do is to sit side by side, an interspecies gathering of descriptions where they might breed or even feast upon each other. We introduce the empirical descriptions that follow with a contextualization of the setting from which they are drawn, and we follow these narrated beasts with a section on bestiary analytics that aims to draw out the effects such juxtapositions can produce. 


\section{Beasts}

As noted above, the beasts of our Bestiary come from all arise within a single research project, Data as Relation, with distinct research sites across the Danish public and private sectors. The potential role for digital data is a topic of high interest in Denmark, which as a nation state is already highly invested in and vocal about digitization processes, expressed in a series of Digital Strategies since 2001 [1,9]. As colleagues within the project have pointed out, transformations in state practices deeply implicate citizens, and both political and institutional work is required to make citizens 'digital' [24]. Our research project's point of departure is that the use of big data and digitization in the public sector is not merely a technical upgrade of existing infrastructures, but implies a reinvention of societal relations ${ }^{1}$. The five beasts presented below are drawn from the subprojects within Data as Relation where research is currently being undertaken by the 14 strong research team.

The authors are exploring sites where the promises of data are being worked with in practice, with fieldworkers entering spaces where contracts are negotiated, technological solutions proposed, potentials weighed and softwares proffered. These are spaces of government administrations, digitization agencies, international data center agreements and health data negotiations. Each of the five illustrations below has a distinct style in thinking through the bestiary as a common project for the collaboration, yet together we have challenged ourselves to use it to pinpoint moments of unease, moments of observation and questions without resolution, which act as analytic openings for keeping the problematic in view. The final beast is focused on the sites where social science research methods are intertwined with the methodological techniques at play in the fieldsites under study: it provides a reflexive commentary on living with the potential for monstrosity within our own fields. What they share is attentiveness to the relations being forged through data practices, and the meeting of the human and the technical. Offered foremost as empirical vignettes, the beasts presented are important for their capacity to surface the concerns or anxieties of those with whom we work, which are sidelined by deadlines, silenced in momentum, or made ephemeral by the affect of rapid transformation. In some cases, this is simply the work of the analyst, in making the familiar strange.

\subsection{Codice Crepitus}

Our first beast is a breed between the software engineering practice 'DevOps' and a large Danish public administration, which we will here call the Processing Authority. 'DevOps' combines the two words 'development' and 'operations', expressing the vision that these should be unified. At a conference in Copenhagen in 2017, advocates for DevOps suggested that DevOps does not only require "cultural change", but the use of software in every step of software development. These advocates projected an image of the so-called "DevOps Metro Map" with approximately 145 'stops' [Figure 1], each

\footnotetext{
${ }^{1}$ See Data as Relation homepage at www.dar.itu.dk
} 
related to particular pieces of software, and the "Periodic Table of DevOps Tools" [Figure 2] with about 120 suggestions for software to use.

Fig. 1.

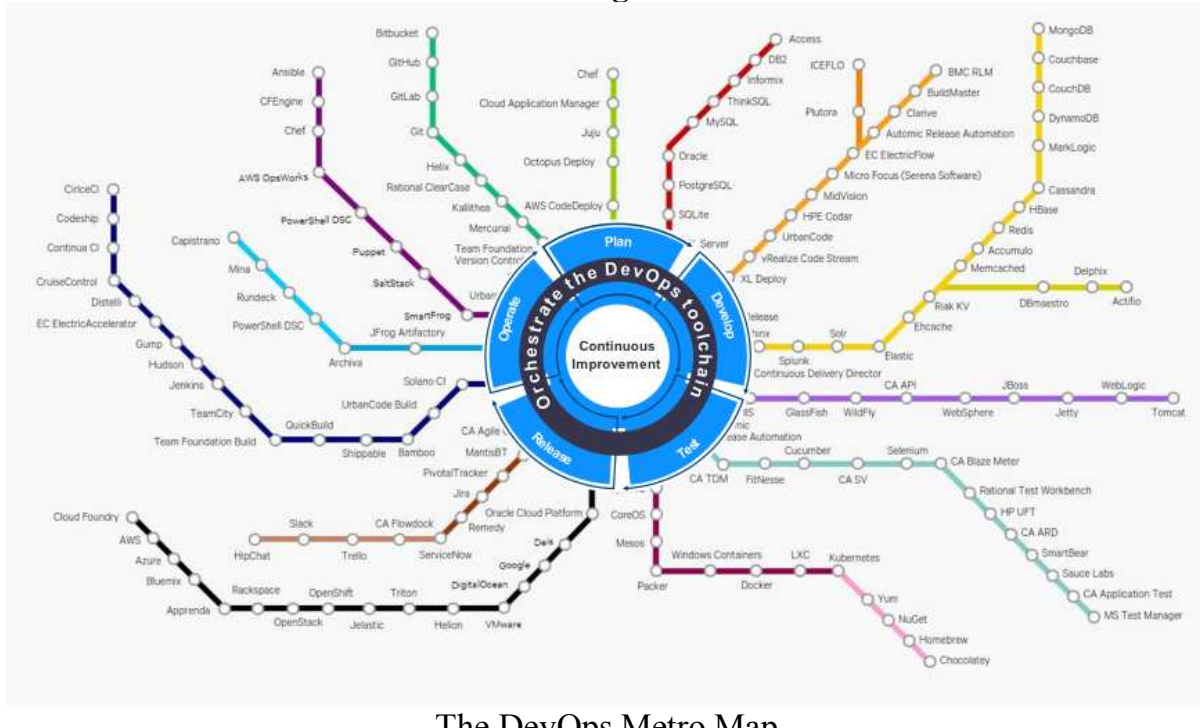

The DevOps Metro Map

One advocate claimed, that if one area was in real need of a digital transformation, it is software development itself. He referred to an article published in the Wall Street Journal in 2011: "Why Software Is Eating the World" [2] Here venture capitalist Andreessen, prompts his readers to accept that software companies are an inevitable part of the future:

... new software ideas will result in the rise of new Silicon Valley-style start-ups that invade existing industries with impunity. Over the next 10 years, the battles between incumbents and software-powered insurgents will be epic. Joseph Schumpeter, the economist who coined the term "creative destruction," would be proud [2]

The idea of "software eating the world" is presented as a good thing, and the enthusiasm with which it is presented resonates with ethnographic experiences. The DevOps work was encountered by Jørgensen during his ethnography of IT projects in the Processing Authority, which is currently developing its own new data platform to share data with other public organizations. This is a change from how the Processing Authority has managed its data: at present, an external consultancy company is in charge, a configuration which does not afford the Processing Authority control of their own data. As a customer rather than an owner, the Processing Authority's command and authority over their systems was troubled, as well as their ability to make further efficiency savings required by ambitious State financial plans.

DevOps was not only a methodological principle in this IT project, it was also the name of a new department. DevOps was related to the administration being "in the 
midst of building an internal IT organization in order to take home a series of the organizations critical IT system" [2].

Fig. 2.
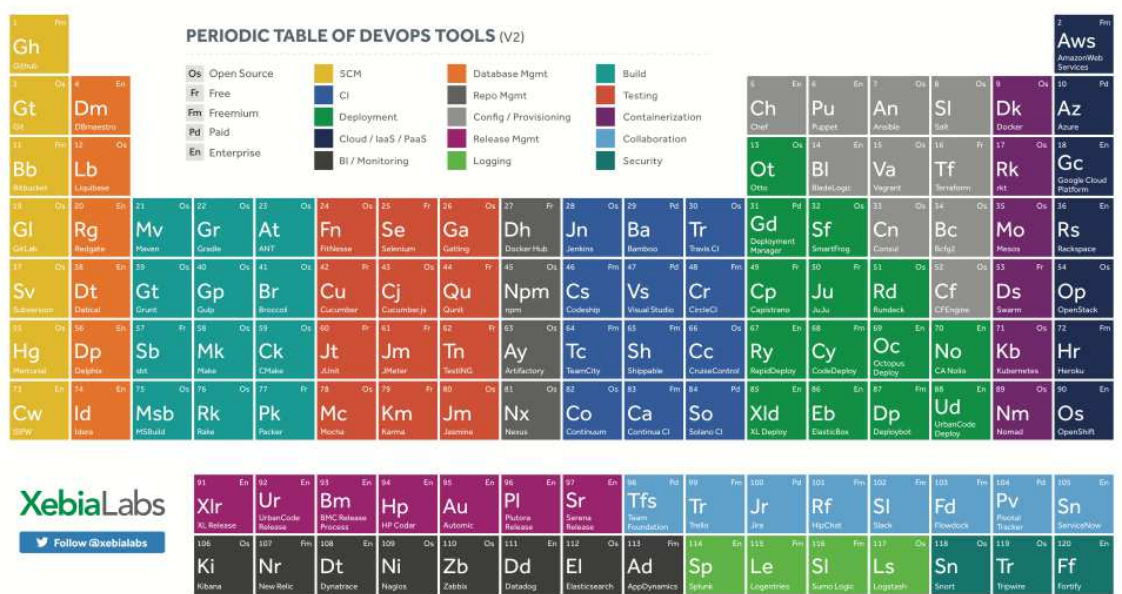

Periodic Table of DevOps Tools

To an observer the combination of DevOps and the Danish Processing Authority seems like a strange beast. On the one hand, we see a wish to become less dependent on external actors - to build the capacity to 'take home' critical systems. On the other hand, the tools considered to do so create new global dependencies. At project meetings, it was not unusual to discuss five or more different software programs of which at least one would be new: Jira, Confluence, Github, Travis, Appdynamics, Redmine are but a few examples of names tossed around. The constant effort to bring new software into the process disconcerted Jørgensen; How could he or his interlocutors ever know any of these programs well enough to decide which ones to include, or how they would work together? And how would the people in the room look back in 5 or 10 years on these new dependencies?

Is it the case, as Andreessen argues, that software is currently "eating the world"? Or is it the hybrid beast of DevOps and the Danish Processing Authority that 'eats' software? One thing seems clear: In the Processing Authority's attempt to get rid of old software dependencies and take home data, the beast simultaneously has to 'swallow' new ones which connects its 'home' to multiple elsewheres.

Viewed through Cohen's breakable postulates, this software story concerns the monstrous problem of excess, of failed containment, a monstrosity that escapes or explodes.

\subsection{Digitalis Dementore}

Our second beast emerges in the meeting of the public and private sectors and their intertwined race to digitalize and become "data-driven". It exists in the proximal future, a data economy that is not yet here, yet somehow already exists. In a subproject focused 
on how digitalization efforts change the internal constitution of the Danish public sector, author Hockenhull examines the role of private sector actors within this process, and examines how futures are summoned into being. Ethnography for the subproject takes place at conferences, workshops and seminars concerned with digital and dataoriented technologies, and over the course of the first year of fieldwork, Hockenhull has become embedded within a public organization currently implementing several strategies to become more "data-driven". From these environs, we detect the contours of a beast lurking behind the scenes, a dampening of the spirit stalking from site to site.

The form of this beast is hard to describe: when first noted, it is innocuous, even common, to the untrained eye. Yet we were alerted to it by the repetition of certain phrases, scenarios and predictions. By the veritable chanting iteration of certain futures, and the interconnection of everything digital. Throughout fieldwork it became apparent that there are startlingly few different imaginaries of what the future of the digital might hold, and that these are repeated across sites; in the form of notions of exponential growth, disruption, unicorn stories and anecdotes about pregnancy tests bought in Target. This is the wraithlike form of the Digitalis Dementore, a gestalt composed of a highly limited set of sociotechnical imaginaries that haunt the dreams and nightmares alike of cutting-edge innovators.

The effects produced by this beast are those of continued sameness and uniformity of thought. Digital technologies and data are presented as both the cataclysmic purveyors of disruptive demise, and as the potential saviors of everything from a company's bottom-line to the cure for all social ills. However most of these imaginaries are frighteningly uniform, dreary and drained of any creative spark or warmth, unsettlingly homogeneous. They postulate worlds of brimming and vibrant Smartness, worlds made commensurable, made manageable, yet inevitably they produce the same "stupid city" [13] and the same business-oriented output.

Describing the Digitalis Dementore is itself a fraught venture, not because its composite imaginaries in themselves are dangerous. Instead, the mere invoking of the beast risks summoning it whilst simultaneously hiding it in plain common-sense sight. Obvious stories, hard to argue against, make themselves at home in confident rhetoric and slick powerpoint slides, becoming impossible to resist. Always its persuasive power is put to work in the service of similar solutions to diverse problems, purchased at a premium from actors who are difficult to hold accountable to their promises.

To describe the Digitalis Dementore is difficult for the above reasons, but it is also the way forward towards learning to live with it. The description itself relies on merriment at the expense of the beast, seeing and repeating its own repetitions in order to show it in a different light. To point out the self-important certainty with which futures are presented, is an attempt to wedge in the possibility that things might be otherwise.

\subsection{Data Delere}

Our third beast stands at the border of what will be permitted to exist and what will not: a monster of Cohen's 'category crisis' [5]. It emerges from the health data sector, where anxieties around access to data have inherited more explicit and sometimes more stringent biomedical models of consent and privacy. Nonetheless, in the autumn of 2014 , a mundane technology designed to automate the collection of primary care data 
and improve the treatment in Danish General Practices rose to public notoriety in Denmark [19]. The data collection project had previously initially been approved for four chronic diseases, yet when the Danish national press broke the story, they revealed that the data collection technology had unlawfully gathered sensitive data from all patient consultations, dating as far back as 2007. No explicit consent had been obtained from the patients and general practitioners, from whom this data had been acquired, who then claimed to be ill-informed about their contribution. The contentious data was stored in a national database. Contentious though it was, it was perceived as invaluable due to its unprecedented detail about primary care and its patients. With interests high and varied, this "golden egg" became the object of a fierce political struggle.

Narrating the controversy is an empirical challenge: it has many twists and turns. Newspapers pursued quotes voraciously and antagonistic formations gathered on new media platforms: the discussion moved on from questions of consent to that of 'what should be done'? As the months passed, public pressure rose, with eventual calls to delete the database. Yet deletion itself proved challenging. And it is here the beast of deletion begins to become visible. In the aftermath of scandal and the technicalities of handling contested data resources, a host of questions were posed to which answers have had to be found. Basic questions were difficult to answer: Where actually was the data? Who had the right to delete it? Under whose domain did it fall? And whose job was it to decide? For months, authorities argued over what should be done, and what was acceptable. Even as government ministries discussed, the National Archives stepped in as an attempt to preserve what was felt as the inherent potential of the data. When the database was eventually deleted, the case became narrative within the landscape of Danish medical data development, continuing to haunt conferences for years afterwards.

In the tussle over normative values placed on patient data, author Burnett found that the tension focused in on the contested database. The monster Data Delere arose not from revelation and loud controversy about a data scandal, but instead the political, institutional and technical intricacies of how a distributed dataset could be deleted. While the work of naming the monstrous in this case came about through news media controversy, it is through following, drawing out the narrative, that the many-headed monster of un-delete-able data becomes visible. Not the monster of breached data rights or of infringed privacy, but of those intricate sociotechnical knots, the tying of which will vary across legal and political regimes [17].

\subsection{A Mithe: Occultis Aperta}

Hidden in plain sight, this fourth beast takes its bestiality from scale, secrecy and concealment. It is the offspring of many different possible futures, of negotiations and promises between alluring tech companies and small municipalities. It concerns the material infrastructure of the data sector: data centers. Spoken of variously as "Engines of the cloud," "brains of the network," "archives of digital capitalism," or "factories of the 21 st century;" data centers can be conceptualized in many ways. As machine-like 
interventions into physical, social, and political landscapes, they are both utterly located; megaprojects that devour land, energy and resources, and entirely distributed; part of planetary wide computational infrastructures. Such doubleness provides openings for productive ambiguity in how data centres take up residency within specific landscapes.

Take the rise of the Big-Tech's (Apple, Facebook, Google) hyper scale data centres. As Europe welcomes Big-Tech's data with open arms, northern states have emerged as the location of choice. The windy landscapes of Denmark are particularly attractive to electricity hungry server farms as they buzz and hum with the acoustics of alternating green electric current. A cool northerly climate, excellent English, a highly organized bureaucracy, and well-developed wind energy infrastructures are some of the things that make the union between the data center industry and the Danish investment sector seem ideal, facilitating technology companies in parading the green credentials of their new European storage and analytics facilities. In turn, Denmark bolsters its credentials as a hyper digitalized state, a place where new forms of digital governance await inception. But the encounter between these large tech corporations and small energy rich welfare states is far from frictionless, as new arrangements of culture and power emerge within it. Such small states do energy collectively, pushing the frontiers of science and innovation to generate phalanxes of wind turbines - on land and sea - in the service of a particular vision of welfarism. And is this welfarism that Big-Tech appropriates in making a home for itself within these landscapes.

While a range of media outlets, experts, and politicians conjure Big-Tech as purveyors of hopeful, promising futures, lurking within such speculative tales is the doubleness that Big-tech's infrastructural composition affords; both here, yet not, resident, yet strange. In appropriating particular strands of Danish state welfarism, the emissaries of hope render Big-Tech as harbingers of future welfare security, bringing to the next generation what prior generations have lost; jobs, opportunities, and infrastructure. So what are the differences that are made? As the emerging, diffractive effects of this encounter begin to unfold - abolishing green taxes, non-green energy, shrouding negotiations in secrecy, silencing participants with non-disclosure agreements - we are beginning to see that the scale of Big-tech's needs (a possible twelve data centers) might just be too much for a small nation state to contain. The energy they consume threatens to outstrip the wind's capacity to provide, (and the windmill's capacity to collect) and the process they invoke threatens to outflank the democratic norms of the state.

A creeping sense of discomfort is emerging as the potential monstrosity of this relationship becomes more palpable. In the same way that the state is struggling to contain the voraciousness of Big-Tech, the opacity of the political form which has given rise to these server farms is struggling to contain an architectural form which has until now, kept them hidden in plain sight.

\subsection{Instrumentua}

Our fifth beast is the offspring of an infatuation with instrumentation, an infatuation that effects ethnographic imaginaries. It comes of a cross-cutting, reflexive component of project work, which is concerned with drawing out relations between Data as Relation subprojects, and with designing research methods tools that will enable 
this kind of collaborative ethnography. Within an imaginary where instrumentation meets the digital, ethnographic material can only come to terms with datafication through the clarification, beautification and amplification offered in the use of computational data analytics. The vision goes like this: already data-fied sites are best ventured into with the assistance of a tolerant beast native to those worlds, an informant which might be persuaded to lend its capacities of alien vision and reasoning. To summon it, the ethnographers need only to make a very careful whisper in the language of Python.

The emergence of this beast is not unique to our project. The competitive social science grant will often include this beast because it is seen to provide an innovative edge. It promises to 'scale up' the ways a project can speak, travel, and garner publics. It promises to transfer mathodological [sic.] learnings of one grant to the next. The hope is that by embracing data analytics systems, a project can materially participate in and interrupt the logics of data. Dressed up ethnography lures funds and new collaborators, new interest. But there is also the lure of the virtualization of ethnography, that by utilizing new platforms to gather, compare, visualize ethnographic material we might achieve parity with the power, legitimacy and futures of the practices we study. That our ethnographic insights could scale, loom larger in the minds of those to whom we might wish to speak. It lures the ethnographer into counterfactual sites, that release the imagination from limitations of the "field", that attempts to crawl, cache, scrape, remember its way into differently bounded analysis, promising field-sites that are unhinged from locale but become increasingly monolithic.

Intimate engagement might train the ethnographer for new ways of seeing and dreaming. And the creature too perhaps learns and takes something back to the data worlds from these border encounters as it travels across sites. Yet this beast can be devouring in its instrumentality: It demands that ethnographic material behave as data, to be "switchable" [18] across different forms of containment in databases for field notes, images, blogs or visualizations. In exchange, it suggests re-adoptability by the ethnographer and their peers. A likeness to tools; lendable, tradable, durable and affordable. Yet, this monster stands at the threshold to becoming [5] stretching out its digits toward the handy ethnographer, as if it already acknowledged how readily it may yet again be abandoned, discarded after completing the tasks asked of it [6]. What inheres in this relation? Could an ethnographer be reasonably trusted to pick bugs crawling off its skin, a care without which this creature would be doomed to the absence of convivial companionship?

\section{Bestiary Analytics}

If change is inherently the site of the monstrous, a world where "humanity has to grasp its future' [16: 196], the sites where people go about explicitly bringing the future into being are the sites to view the difference those monsters make. Yet of course each of these manifests in distinct forms. Bringing beasts together in a bestiary foregrounds 
acts of noticing, analysis of making, and objectification. As much as attending to those things which get called out as monstrous (a way of 'reading cultures from the monsters they engender' [5:3]) we attend to monsters in the making. In a departure from cultural theory's engagements with the beasts of popular culture, our bestiary carries an ethnographic sensibility, calling us as analysts to account for what we describe into being.

In the cases described above, monstrosity emerges through narration, seeing, and engagement. The beasts we describe emerge from the specificity of our Danish research settings, yet we suspect that beasts of these types can be described across research site boundaries. Digital ubiquity poses a certain methodological challenge to scholars of data and its lives, and as researchers, we carry expectations about the capacity to bound our fields of study, to organize analytically what will fall within and outwith those worlds. Yet through a bestiary of digital monsters, we would hope to bring out some of the observations both of those with whom we work (such as software engineers, data center designers, or platform builders) and of our own as researchers. For example, we could probably fill an entire shelf of bestiaries with cousins of Codice Crepitus, a series of tales whereby the lives of outsourced projects and the lure of in-house data analytics advantages are giving rise to disconnects between software development styles and management practices: in these muddles, those with whom we work find monstrous tangles, and our descriptions can give voice to this complexity. Digitalis Demontore is similarly visible only through long term immersion in the sites that characterize themselves as the forefront of change. Sited within the spaces where those whose visions seek practical instantiations and technical skills, repeated slides and phrases that work, but lose meaning. The patient and attentive ear can begin to hear the murmurings of a monster that is the opposite of what it claims: imaginaries that compose Digitalis Demontore are themselves everyday, contestable, but it is their uniformity and persuasive power and the downstream effects of buying into these that are monstrous.

Through its form of narrative juxtaposition, the bestiary allows us to attend to the politics of our analyses, and the language of description we use. Levina and Bui argue that monstrosity has "transcended its status as a metaphor and has indeed become a necessary condition of our existence in the twenty-first century" [20:2], both producing and representing the changes of twenty-first technological "monster culture" [5]. A similar move takes place for information technologies, which - in the words of the conference call-'no longer merely represent the world, but also produce it'. Taking this performativity seriously, the digital cannot be considered 'other' to 'the human' nor as a metaphor for human life. We should not describe it as such. In response to the presentday ubiquity of digital endeavors, this kind of analysis allows us to find "a way of staying in the same plane of knowing" as those whom our stories about monstrosity are about [26], a practice known as laterality [11, 12, 19]. Defying the boundary between emic and etic, laterality is a move that refuses the privileging of an academic, theoretical perspective over that of interlocutors or collaborators. In the juxtaposition of the beasts above, we can see stories of frustrations, fears and forms of anger brought about by technological changes. Data, not least its concomitant sense of possibility and volume, brings people and technologies into new relations around future-making. Would a fuller, richer bestiary inspire new ways of deliberating and conversing about or even laugh about monstrous, digital technologies? 
Above all, in its inherent refusal of totality the bestiary makes different kinds of cuts in analytical fields. More than ever before, field connections are partial [25]. We envision, for one thing, that the bestiary opens up for participation. As much as our project has benefited from the work of describing technological anxieties that take monstrous form, so might other common projects. A bestiary can travel: in this case, through publication. In continuity with bestiaries of old, fables of the monstrous technological present resonate with fables of the medieval bestiary in their capacity to inspire analogical learning. For early bestiaries, the moral question was precisely about thinking across the different 'species': What could be learned about human ways of life from various depictions of the worlds of creatures? If today, living with the technologically monstrous is part of the human condition, perhaps the question is not so much a matter of analogical learning across species, as it is about finding and depicting monstrosity in specific encounters. Or, as MacCormack puts it (in the spirit of the project from which these cases emerge) in the 'study of relation more than of an object' [21:305].

\section{Conclusion}

In a moment which feels full of the monstrous, we argue that it is necessary to describe the monsters we encounter in our research with care. Rather than reveling in the reveal and staying within its shock value, monstrosity can be approached as a revelatory way of knowing the technologies that traverse disparate systems of value. Cohen tells us that the monster 'always escapes' [5] and the impossibility of knowing it in its entirety is part of what makes it monstrous. In using the monstrous as a construct through which to understand our present moment of technological anxiety, we have worked through a series of cases from an emergent bestiary. Asking about the kind of relations are possible with monsters necessitates an enquiry into what makes monsters monstrous. Although we have named our beasts, our Bestiary is more focused on the processes of technological making that bring about moments of unease, and the role of description in drawing the eye to the monstrous, than the satisfactions offered by taxonomies. They demonstrate moments of breach in the making of contemporary technological realities, resonances with earlier monsters, and worlds of monsterly haunting. Yet like Borges' Celestial Emporium of Benevolent Knowledge, the monsters of our bestiary illustrate the limits of classificatory schema upon the monstrous, recalling Foucault's laughter upon reading Borges's list, which for him, 'shattered ... all the familiar landmarks of thought —our thought, the thought that bears the stamp of our age and our geography — breaking up all the ordered surfaces and all the planes with which we are accustomed to tame the wild profusion of existing things' [10: 1]. Analysis may seek this accustomed taming, but, it may sometimes need to encounter such a break with the familiar landmarks of thought that taming ceases to be the objective. Keeping both forms of monstrosity in sight is the task of a reflexive critical analysis, and perhaps, a bestiary analytics. 


\section{References}

1. Agency for Digitisation.:A Stronger and More Secure Digital Denmark: The Digital Strategy 2016-2020. (2016).

2. Andreessen M (2011 Why Software is Eating The World. Wall Street Journal. Available at: https://www.wsj.com/articles/SB10001424053111903480904576512250915629460 or https://a16z.com/2016/08/20/why-software-is-eating-the-world/

3. Badke, D.: Introduction. The Medieval Bestiary, http://bestiary.ca/intro.htm, last accessed 2018/05/30.

4. Biles,J.: Monstrous technologies and the telepathology of everyday life. In: Levina, M., Bui, D-M. T. (eds.) Monster Culture in the 21st Century, pp. 147-162. London, Bloomsbury (2013).

5. Cohen, J. J.: Monster Culture: Seven Theses. In: Cohen, J. J. (ed.). Monster Theory, pp. 326. Minnesota University Press, Minneapolis (1996).

6. Cohen, J. J.: Postscript: The Promise of Monsters. In: Mittman, A. S., Dendle, P. J. (eds.). Ashgate Research Companion to Monsters and the Monstrous, pp. 449-464. Ashgate, London (2012).

7. Derrida, J., Weber, E.: Points...: Interviews, 1974-1994. Stanford University Press, Stanford (1995).

8. Dourish, P, Bell, G. Divining a Digital Future. MIT Press, Boston (2011).

9. Dunleavy, P.,Margetts, H., Bastow C., Tinkler J. Digital Era Governance: IT Corporations, the State and E-Government. Oxford University Press, New York (2006).

10. Foucault, M.: On the Order of Things. Routledge, London (2005).

11. Gad, C., Jensen, C. B. \& Winthereik, B. R.: Practical Ontology : Worlds in STS and Anthropology. NatureCulture 3, 67-86 (2015).

12. Gad, C., Bruun-Jensen, C.: Lateral Concepts. Engaging Science, Technology and Society 2: 3-12 (2016). DOI: 10.17351/ests2016.77

13. Greenfield, A.: Against the Smart City. Do Projects, New York (2013).

14. Haraway, D.: The Promises of Monsters: A Regenerative Politics for Inappropriate/d Others. In: Grossberg, L., Nelson, C., Treichler, P. (eds.). Cultural Studies, pp. 295-337. Routledge, New York (1992).

15. Haraway, D.: Staying with the Trouble. Duke University Press, Durham, NC(2016).

16. Hardt, M., Negri, A.: Multitude: War and Democracy in the Age of Empire. Penguin Press, New York (2004).

17. Jasanoff, S.: Designs on Nature: Science and Democracy in Europe and the United States. Princeton University Press, Princeton, NJ (2005).

18. Kittler, F.: Realtime analysis, time axis manipulation. Public Culture13(1),1-18(2017).

19. Langhoff, T.O., Amstrup M. H., Mørck P., Bjørn P. Infrastructures for healthcare: From synergy to reverse synergy. Health Informatics Journal 24(1):43-53 (2016).

20. Levina, M., Bui, D-M.T.: Introduction. In: Levina, M.,Bui, D-M.T.(eds). Monster Culture in the 21st Century, pp. 1-14. Bloomsbury, London (2013).

21. MacCormack, P.: Posthuman Teratology.In: Mittman,A.S.,Dendle, P. J.(eds.).The Ashgate Research Companion to Monsters and the Monstrous, pp. 293-309. Ashgate, London (2013).

22. Maurer, B.: Mutual life, limited: Islamic banking, alternative currencies, lateral reason. Princeton University Press, Princeton, N.J. (2005). 
23. Mittman, A. S.: Introduction: The Impact of monsters and Monster Studies. In: Mittman, A S., Dendle, P. J. (eds.). The Ashgate Research Companion to Monsters and the Monstrous, pp. 1-16. Ashgate, London (2012).

24. Schou,J., \& Hjelholt, M.: Digital citizenship and neoliberalization: governing digital citizens in Denmark. Citizenship Studies 22:5, 507-522 (2018).

25. Strathern, M.: Partial Connections. Rowman \& Littlefield, London(2004).

26.Verran,H.:Workingwiththosewhothinkotherwise.CommonKnowledge,20(3),527-539

(2014).

27. Winthereik, B., Verran, H.: Ethnographic Stories as Generalisations that Intervene. Science Studies 25 (1), 37-51 (2012).

28. Weinstock,J.A.:InvisibleMonsters:Vision,HorrorandContemporaryCulture.In:Mittman, A. S., Dendle, P. J. (eds.). Ashgate Research Companion to Monsters and the Monstrous, pp. 275-292. Ashgate, London (2013). 